\title{
DEMETRIO TRICLINIO EN SU CENTENARIO *
}

\begin{abstract}
Demetrius Triclinius, the very important Byzantine scholar, was born at Thessalonica around 1280 and lived along the reigns of Andronicus II and Andronicus III Palaeologus. We may therefore place somewhere in the present decade the commemoration of the seventh centenary of his birth. This homage is certainly well deserved by a philologist who prepared and improved many editions of Greek authors, specially the tragic poets, with an extraordinary competence and acumen. $\mathrm{He}$ is one of the few among his contemporaries who worked with a true philological method and this fact distinguishes him from them and allows us to view Triclinius as a true predecessor of the Renaissance Humanists.
\end{abstract}

El estupendo libro de Hunger ${ }^{1}$ sobre la Literatura profana bizantina da la fecha de ca. 1280 para el nacimiento de Demetrio Triclinio. No es, pues, ningún disparate, y la mencionada preposición me autoriza a ello, pensar que el excelente filólogo pudo nacer en 1283; lo cual permite incluir, aunque un tanto abusivamente - pero estas conmemoraciones, como los santos, tienen octava-, su nombre en la larga lista de los centenarios de este año.

Aquí tendríamos, pues, la merecida y creo que única celebración que nadie haya dedicado al séptimo centenario de Triclines; pues como

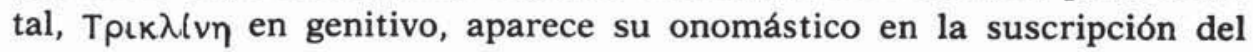
códice oxoniense ${ }^{2}$ firmada en 1308 , mientras que en las del hesiodeo de la Marciana, de 1316 y 1319, encontramos ya ${ }^{3}$ Tpı.k $\lambda$ เvlou como muestra de un prurito arcaizante algo pueril del que es paralelo, en el mismo manuscrito, el intento de restauración, que nadie aprobó, de las medias

* Trabajo presentado a las III Jornadas sobre Bizancio (Madrid, mayo de 1983).

1 H. Hunger, Die hochsprachliche profane Literatur der Byzantiner II, Munich 1978 , p. 73 (a los filólogos de la época de Triclinio en general están consagradas las pp. 67-77).

2 Cód. Oxon. New Coll. 258; cf. R. Aubreton, Démétrius Triclinius et les recensions médiévales de Sophocle, París 1949, p. 21.

3 Cód. Ven. Marc. gr. 464; cf. R. Aubreton, ibid. 
etas con forma de martillo en lugar de los espíritus áspero y suave que habían venido redondeándose en los siglos anteriores ${ }^{4}$. Y un no menos adecuado homenaje a ciudad tan humanística como Tesalónica, que desde hace algo más de tres lustros no sólo puede asegurar que en ella residió Triclinio, sino también, gracias a la publicación por Wasserstein de un tratado astronómico consagrado a la luna que había quedado inédito 5 , envanecerse de haber sido su opulenta ciudad natal según su

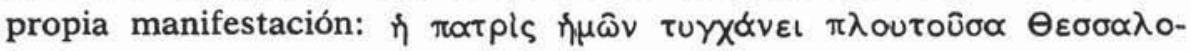
$v i k \eta$.

Cuando nació Demetrio quedaba ya muy lejos el triste 13 de abril de 1204, en que la barbarie de los Cruzados, acaudillados por el anciano y ciego dogo veneciano Enrico Dandolo y el intrigante Bonifacio de Montferrat, futuro rey precisamente de Tesalónica, iba a traer lo que llama Hunger ${ }^{6}$, con deformación profesional de filólogo, "una lamentable cesura en la vida política y cultural de los Bizantinos». Bien conocidas resultan al respecto las acaloradas protestas del historiador Nicetas Choniates, mal llamado Akominatos, autor de una Xpovıki

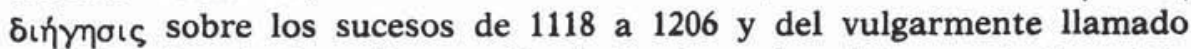
en latín De signis o De statuis, dedicado a describir con indignación las esculturas destruidas por los invasores en la capital tomada aquel día. Hasta los Sarracenos - clama- son bondadosos y compasivos en comparación con aquellos conquistadores «que llevaban la cruz de Cristo en sus espaldas" ${ }^{7}$; y el principal cronista occidental del acontecimiento, aunque naturalmente con distinto enfoque, deja entrever también el horror de aquella jornada al afirmar que «bien atestigua Godofredo de Villehardouin, el mariscal de Champana, porque lo sabe y porque es verdad, que, desde que comenzaron los siglos, jamás se ha conquistado tanto botín en una plazam ${ }^{8}$.

La feroz depredación pudo, debió haber marcado el fin del doliente Imperio; pero entonces empiezan los increíbles milagros. En 1205, sola-

4 Cf. E. Fraenkel, Aeschylus. Agamemnon I, reimpr. Oxford 1962, p. 3, n. 3; A. Turyn, The Byzantine Manuscript Tradition of the Tragedies of Euripides, Urbana, Ill., 1957, pp. 26-28.

5 Cf. A. Wasserstein en p. 163 de «An Unpublished Treatise by Demetrius Triclinius on Lunar Theory», en Jahrb. Oesterr. Byz. Ges. 16, 1967, pp. 153-174.

6 H. Hunger, o. c., p. 67 («eine empfindliche Zäsur im politischen und kulturellen Leben der Byzantiner»).

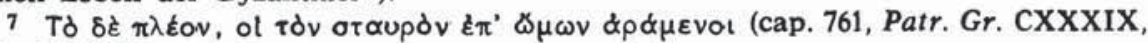
cols. 958-959).

8 «Et bien tesmoigne Joffrois de Vile-Hardouin, li mareschaus de Champaigne, à son escient par verté, que puis que li siecles fu estorez, ne fut tant gaainnié en une vile* (La conquête de Constantinople, ed. Wailly, p. 146; tomo la cita de G. Ostrogorsky, Geschichte des byzantinischen Staates, Munich 1940, p. 297, n. 2). 
mente un año después de la caída de Bizancio, muere Dandolo y el efímero emperador Balduino de Flandes pierde su trono y su libertad en humillante derrota ante el zar búlgaro Kalojan; desde 1206, una nueva dinastía se afirma en la minorasiática Nicea con buenos emperadores como Teodoro I Láscaris y Juan III Ducas Vatatses; los sultanes selyucíes de Iconio o Konya, aterrados ante el empuje mongol y tártaro, que se extiende indomable por Rusia, los Balcanes y Europa central, no sólo resultan de momento inofensivos para los nuevos gobernantes, sino que se ven obligados a pedirles ayuda en 1243; tres años después, la que iba a ser patria de Triclinio, escenario sucesivo del breve reinado de Bonifacio, muerto en 1207 luchando también contra los búlgaros, y, desde 1224, del de otros reyezuelos epirotas, pasa finalmente a manos del dinámico Vatatses, que antes de morir en 1254 pudo ver coronada su racha de éxitos con la anexión de todo el Epiro.

La estancia de la corte y capital en la provincial Nicea, se ha dicho muchas veces, representó una alentadora bocanada de aire fresco, un baño de autenticidad para el sofisticado y corrupto imperio constantinopolitano. «Una fiel nobleza, mandada por emprendedores y piadosos emperadores, gobernó y acaudilló durante medio siglo a un pueblo de pastores y campesinos de costumbres y modales simples». Acertadas palabras de un historiador'; pero también supieron intuir los representantes de aquella familia que, como tantas veces ocurre, probable y casi paradójicamente la salvación de una civilización amenazada por todos los salvajismos de Oriente y Occidente estaba en las Humanidades. El hijo de Vatatses, Teodoro II Láscaris, que había de reinar cuatro años desde la desaparición de su padre, era un verdadero humanista, filósofo, teólogo, filólogo, alumno del famoso Nicéforo Blémides. Nicea, impregnada de sabios empeños bajo su guía, se convirtió, según afirma de modo quizá algo hiperbólico el patriarca Gregorio de Chipre, en una segunda Atenas; y Teodoro Metoquita, el gran político e intelectual de la corte de los Paleólogos, apuntaba en un elogio retórico de aquella ciudad que tuvo el mérito de conservar la semilla de una verdadera

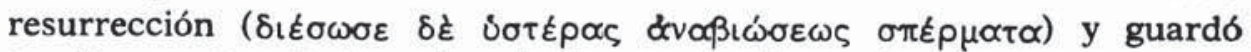
los fragmentos destrozados de la gran cultura de antaño como una valiosa prenda ( $\pi \propto \rho \propto \kappa \propto \tau \propto \theta \eta \kappa \eta \eta)$ que sería devuelta a su legítima propietaria Constantinopla cuando dejaran de profanarla sus ignorantes e infieles dueños ${ }^{10}$.

9 N. Iorga, Histoire de la vie byzantine III, Bucarest 1934, p. 120; tomamos la cita de N. H. Baynes - H. St. L. B. Moss, Byzantium. An Introduction to East Roman Civilization, Oxford, reimpr. 1962, p. 35.

10 Cf. H. Hunger, 1. c. en n. 6. 
Tal ocurrió en otra fecha memorable. El 15 de agosto de 1261, Balduino II huye, el Imperio latino desaparece y la urbe ve entrar triunfalmente en ella a Miguel VIII, coemperador desde tres años atrás con el monarca niño Juan IV a quien pocos meses después había de cegar cruelmente.

Con ello se entronizaba una nueva dinastía, la de los Paleólogos, a la que quedaba reservado el amargo trance mortal de la nueva Roma. Triclinio tenía solamente dos años cuando murió Miguel VIII y no pudo, por tanto, apreciar personalmente las calidades y los defectos de un emperador más brillante que positivo al que alucinaron demasiado las luces cada vez más atractivas de Europa. Pero, en cambio, si, como se supone, murió hacia el 1340 , a edad relativamente avanzada para el promedio de entonces, ello le habrá permitido vivir íntegro el largo reinado de Andronico II, emperador desde 1282 hasta 1328, y todo o casi todo el de Andronico III, muerto en 1341.

No habían ciertamente de escasear las desdichas a lo largo de uno y otro. Andronico II es en lo político el emperador de la devaluación monetaria, la opresión fiscal, el descontento entre los mal pagados acritas de la frontera, el asesinato de Roger de Flor y la venganza catalana; su nieto, el de las guerras civiles, los movimientos religiosos y el amenazador apogeo de Serbia. Pero lo peor es que en un Oriente algo más tranquilo en cuanto a los Mongoles, dispersos en muchos frentes - falta más de medio siglo para que Tamerlán traiga el último respiro a la agónica ciudad-, ha surgido otro pueblo turco más peligroso y eficaz. Cuando Demetrio contaba cuarenta y seis años aproximadamente, la recién conquistada Brusa, convertida en capital de los otomanos, fue ya la ciudad santa que contendría el sepulcro del también recién fallecido Osmán; cinco después el dominio de Asia Menor es total con la captura nada menos que de Nicea, la antigua metrópolis.

Y, entre tanto, una Bizancio impertérrita ante la catástrofe sigue trabajando, leyendo, estudiando a los clásicos griegos y latinos. Andronico II, erudito, piadoso, más bien débil de carácter, aquel a quien se ha declarado " más apto para una cátedra de Teología que para un enorme y complicado Imperio, se rodea de toda una constelación de competentes intelectuales ${ }^{12}$. Triclinio ya no pudo conocer al citado Nicéforo Blémides, muerto ocho años antes de su propio nacimiento, insigne

11 Tomo la cita de N. H. Baynes-H. St. L. B. Moss, o. c., p. 41.

12 «Wenn das Zeitalter der Palaiologen die Epoche einer einzigartigen Blüte von Wissenschaft und Kunst war, wenn Konstantinopel trotz des politischen Verfalls ein intellektuelles Zentrum der Welt blieb, so war das nicht zuletzt ein Verdienst des viel geschmähten Andronikos II» (G. Ostrogorsky, o. c., p. 342). 
enciclopedista de cuño aristotélico; pero su cronología se aproxima bastante a las de dos famosos maestro y discípulo, el también aludido Teodoro Metoquita y Nicéforo Gregoras. Senador, diplomático, primer ministro o $\mu \varepsilon \sigma o ́ \alpha \zeta \omega \nu$ de Andronico el primero, pero también restaurador del célebre monasterio de Chora, en que pasaría sus últimos años como monje Teolepto ${ }^{13}, \mathrm{y}$, antes y después de ello, retórico, poeta, crítico; increíble trabajador el segundo, embajador él también, astrónomo y reformador del calendario, orador, teólogo, historiador, filósofo, gran platonista, precursor, en una palabra, de los Vallas, Ficinos y Polizianos de algo más de un siglo después.

Pero aquí me interesan en mayor grado cuatro personajes más estrictamente filológicos, cuyos datos resultan unas veces paralelos y otras quiásticos entre sí y que en conjunto constituyen una imponente escuela. Son, por orden de nacimiento, Manuel (Máximo en la vida religiosa) Planudes (que vive entre 1255 y 1305), Manuel Moscopulo (nacido hacia 1265), Tomás Magíster (que vivía hacia 1346 y que debió de alcanzar unos 75 años) y Demetrio Triclinio, cuyas fechas ya conocemos. El segundo es natural de Constantinopla, y probablemente también el primero; ambos laboran en el citado monasterio de Chora. Planudes, maestro de Moscopulo, escribe a un tío de este último, obispo de Creta: "Tu sobrino asiste a clase con celo, pero enseña con más todavía" ${ }^{14}$. Lo cual permite deducir que el futuro filólogo era lo que hoy llamaríamos un alumno de tercer ciclo, encargado simultáneamente de dar lecciones a los principiantes.

Máximo ${ }^{15}$ es con toda probabilidad un hombre peritísimo e inteligente; se interesa, y ello es rasgo original, por el latín y traduce al griego infinidad de clásicos de esta lengua: Cicerón, Ovidio, Juvenal, S. Agustín, Boecio ${ }^{16}$. Y, cuando se enfrenta con lo helénico, no busca precisamente tareas simples: edita a Píndaro, algo más trillado por entonces, redacta escolios para Hesíodo y Tucídides, pero también se atreve con ediciones de Arato, Esopo, Plutarco (en trabajo que no llegó a terminar), el geógrafo Ptolemeo, el matemático Diofanto; comenta a Euclides; lleva a cabo un magnífico logro con su colección, conservada hoy por un códice florentino ${ }^{17}$, de muchos autores hexamétricos, uno

13 Cf. I. Sevcenko, Theodore Metochites, the Chora and the Intellectual Trends of his Time, en The Kariye Djami IV, Princeton, N. J., 1975, pp. 19-91.

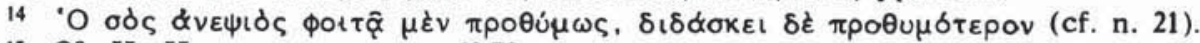

15 Cf. H. Hunger, o. c., pp. 68-70.

16 Sobre Planudes como traductor, cf. W. O. Schmitt, «Lateinische Literatur in Byzanz. Die Uebersetzungen des Maximus Planudes und die moderne Forschung», en Jahrb. Oesterr. Byz. Ges. 17, 1968, pp. 127-147.

17 Cód. Flor. Laur. 32, 16 (S de Hesíodo en la ed. de Solmsen). 
de los cuales, Nonno, se habria perdido sin su intervención; copia personalmente hacia el 1300 unos 2.400 epigramas que en general están también en los códices heidelbergense y parisino de la Antología ${ }^{18}$, pero 388 de los cuales, el mal llamado libro XVI de la misma, sólo a él y al manuscrito conservado en Venecia ${ }^{19}$ deben su preservación. Y se esfuerza - lo cual es hoy método banal, pero alguien tenía que empezar- por llevar a cabo serias colaciones, como cuando pide a Manuel Brienio «tu códice de Diofanto... porque quiero compararlo con el mío...» ${ }^{20}$.

Moscopulo ${ }^{21}$ parece haber sido algo inferior a su maestro: probablemente vio implicada su citada actividad tutorial con los absurdos métodos esquedográficos ${ }^{22}$ de enseñanza y aprendizaje, a base de fatigosos análisis, memorismos y ficheros (nuestro filólogo es autor de un

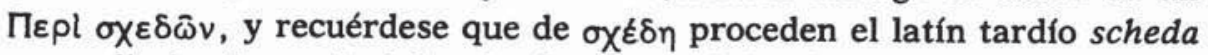
y su diminutivo schedula, de donde «cédula, ficha»), que dominaban

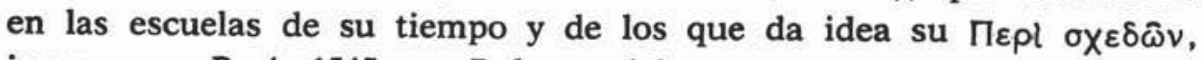
impreso en París 1545 por Roberto Etienne y que centra sus enseñanzas de griego en $22 \sigma \chi \varepsilon \delta \propto \alpha$ o comentarios gramaticales: seis textos religiosos, cuatro parenéticos ( $\pi \delta ́ v o \iota ~ \gamma \varepsilon v \nu \omega ̂ \sigma \iota ~ \delta \delta \xi \alpha v$ ), una fábula de Esopo y once relatos mitológicos, casi todos relacionados con el libro I de la Itiada. Carlo Gallavotti acaba de dedicar un buen estudio a estas actividades y serfa muy interesante que se confirmara su tesis de que la esquedografía no fue ni mucho menos inventada por Moscopulo, sino que se remonta al gran Teodoro Pródromo, cuya vida se desarrolló entre 1100 y 1170, es decir, en la época de los últimos Comnenos, Alejo I, Juan II y Manuel I. El caso es que esta fatigosa tarea pudo haber esterilizado parte de su trabajo, reducido por lo visto a las Olimpicas de Píndaro y las tríadas (respectivamente Ayante, Electra, Edipo rey y Hécabe, Orestes y Fenicias) de Sófocles y Eurípides. Lo cual no le quita grandes méritos, como su manera cortés y apacible de enfrentarse con sus colegas, frente a conductas que ahora veremos, y no pocas ideas acertadas ${ }^{23}$.

\footnotetext{
18 Códs. Heidelb. Palat. 23 y Paris. Suppl. gr. 384 (P).

19 Cód. Ven. Marc. gr. 481 (Pl).

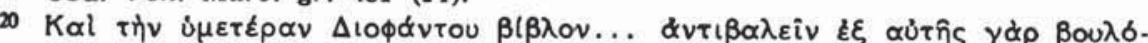

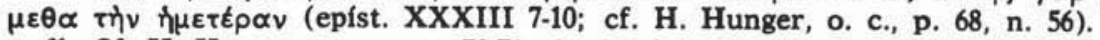

21 Cf. H. Hunger, o. c., pp. 70-71, de donde procede nuestra cita de n. 14.

2 Cf. H. Hunger, o. c., pp. 22-29; C. Gallavotti, «Nota sulla schedografia di Moscopulo e i suoi precedenti fino a Teodoro Prodromo», en Boll. Class. 4, 1983, pp. 3-35.

23 Cf. A. Turyn, o. c., p. 113; H. Hunger, o. c., p. 71, n. 75.
} 


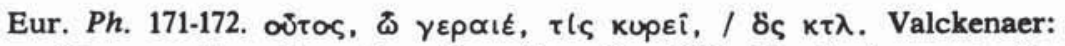

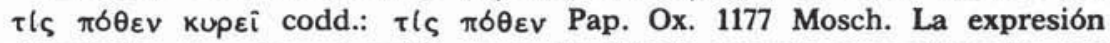
abreviada $\tau(\varsigma \pi \delta \theta \varepsilon v$ («quién es y de dónde procede»), confirmada por el pap., ha dado lugar a la adición antimétrica de кupeí, que no debió haber suplantado al adv. en la conjetura.

No era tal ciertamente el proceder de Tomás, componente mayor -y tal vez superviviente- de la pareja de filólogos de Tesalónica, ciudad en que residió, aunque no consta que en ella naciera. Hunger ${ }^{24}$ nos lo presenta como prototipo del genus irritabile philologorum, por desgracia demasiado abundante en todas las épocas, hoy quizá menos que en otras. Magíster se hallaba persuadido de su propia infalibilidad ( “isoy yo quien lo dice!» ${ }^{\varpi}$ ) y tachaba a sus predecesores y colegas de «incultos», «ignorantes» y "charlatanes»; en cuanto a él mismo, centrado principalmente en Píndaro, Esquilo y Sófocles, no acierta siempre en cuanto a sintaxis, intenta absurdamente convertir los trímetros yámbicos en dodecasílabos bizantinos, pero tampoco anda escaso de cierto olfato inherente a una larga convivencia con los clásicos ${ }^{26}$.

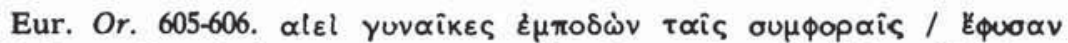

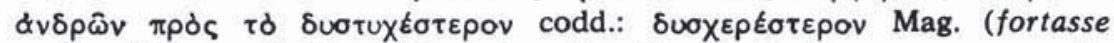
melius Musgrave). Es evidente banalización la de los mss., provocada

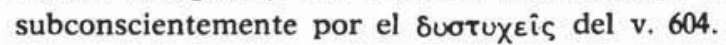

Y finalmente, como colofón y pináculo de este importante taller filológico que identifica Hunger ${ }^{27}$, con referencia a los cien años que median entre 1250 y 1350 , como productor de una gran parte de los más antiguos y mejores manuscritos de autores griegos de los períodos clásico e imperial, he aquí a nuestro Triclinio, que probablemente fue discípulo de Magíster y solamente mantuvo relaciones superficiales con Moscopulo, a juzgar por la observación de Irigoin, según el cual ${ }^{2 s}$ en

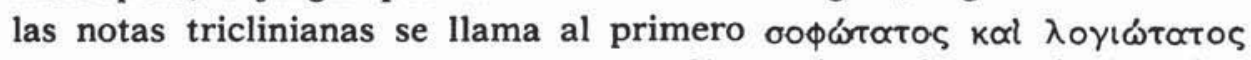
kúpıos y al segundo kúpıo̧ solamente. Si es así, con la especie de quias-

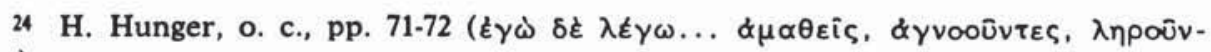
$\tau \varepsilon \varsigma)$.

25 Cf. A. Turyn, o. c., p. 168, n. 182.

26 G. Zuntz, An Inquiry into the Transmission of the Plays of Euripides, Cambridge 1965 , pp. 152-153.

27 Cf. H. Hunger en pp. 124-125 de $\propto$ Von Wissenschaft und Kunst der frühen Palaiologenzeit», en Jahrb. Oesterr. Byz. Ges. 8, 1959, pp. 123-155; n. 51 de 1. c. en n. 6; U. von Wilamowitz-Moellendorff, Euripides. Herakles I, Berlín $1895_{2}$, p. 195 ( $₫$ Die Byzantiner sind eigentlich gar nicht als Schreiber, sondern als Emendatoren aufzufassen...; pero cf. infra).

28 J. Irigoin, Histoire du texte de Pindare, Paris 1952, p. 331, n. 2. 
mo de que antes hablé se invierten las valoraciones respecto a Planudes y Moscopulo de modo que en este caso es el alumno quien supera al profesor.

Hunger ${ }^{29}$ hace notar muy sensatamente las grandes fluctuaciones que viene sufriendo la estimación de los eruditos de la época de los Paleólogos. El siglo xIX les imputaba estrechez de criterio, falta de conocimientos lingüísticos, mera estupidez ${ }^{30}$; pero yo añadiría que esto comenzó incluso antes. Aubreton ${ }^{31}$ dedica un interesante capítulo al contrapunto de opiniones entre el gran Turnèbe, que sigue ciegamente a Triclinio en su edición sofoclea de $1553{ }^{32}$; Canter, que en la suya, de a partir de 1579, cree preciso dar la razón siempre al antiguo filólogo cum... Triclinium... maximi omnes faciant; el agudo Enrique Estéfano, quien en la de 1603 observa sobre un pasaje que Triclinius suo more nodum... in scirpo quaerit (busca nudos en el liso junco, algo así como tres pies al gato) y dice haber hecho ciertos distingos ut cautionem in legendis eius scholiis adhibendam esse docerem; y finalmente Ricardo Francisco Felipe Brunck, en cuyas notas al texto de Sófocles, publicado en $1786^{33}$, leemos a cada paso intemperantes opiniones sobre los métodos de Triclinio, hijos de su libido o arbitrariedad ${ }^{34}$, de su socordia o negligencia ${ }^{35}$. Para el dogmático alsaciano, militar por cierto además de helenista, el bizantino es un stolidus... graeculus, un estúpido grieguecillo; maneja los coros impudentissima audacia... insulsissima quaeque inferciens; sus lecciones no son sino elucubraciones de un torpe cerebro ${ }^{36}$; Turnèbe es digno discípulo de su maestro, al que obedece como a quien dictara oráculos desde el trípode délfico ${ }^{37}$, etc. $\mathrm{Y}$ así continua pontificando, cuando no despotricando, la centuria pasada, pero con la importante discrepancia del maestro Wilamowitz, que, con su apasionamiento habitual, se excede, creo yo, al poner en los cuernos de la luna ${ }^{38}$ al tesalonicense: «Demetrio Triclinio es realmente más bien el primer crítico moderno de la poesía trágica que un poco fidedigno seguidor de la tradición textual... Poseía

\footnotetext{
29 H. Hunger, 1. c. en n. 1.

30 «Engstirnigkeit, mangelnde Sprachkenntnisse und Stupidität».

31 R. Aubreton, o. c., pp. 239-274.

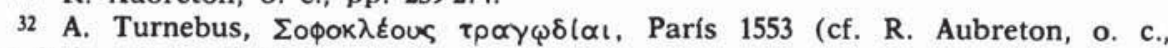
pp. 27-29, 41-45 y 240-246).

33 R. Fr. Ph. Brunck, Sophoclis quae extant omnia, Estrasburgo 1786.

34 Triclinii libidini debetur (sobre Oed. R. 917).

35 Ibid.

36 Sobre $E l .852$

37 Novus noster Triclinius ista, tanquam si a tripode edictata fuissent, venerabundus amplectitur (sobre El. 226).

38 U. von Wilamowitz-Moellendorff, 1. c.
} 
no escasos conocimientos métricos no aprendidos en los libros, sino procedentes de la observación ${ }^{39}$, y sobre todo", con expresión muy típica del temple prusiano, racionalista y protestante de Wilamowitz, "er hat Erfolg gehabt», ha tenido éxito.

La verdad, como casi siempre, está en el término medio. Recorramos rápidamente algunos juicios sobre la labor de Demetrio en torno a Píndaro y los trágicos, objetos principales de su estudio, aunque también editó de joven a los retores Aftonio y Hermógenes ${ }^{40}$, precisamente en el códice de Oxford antes citado por $\mathrm{mí}^{41}$, y luego a Hesíodo, Aristófanes y Teócrito; es decir, como anota Irigoin ${ }^{42}$, a todos los autores poéticos que se estudiaban en su tiempo salvo Homero.

Esta manifestación la hace el colega de la Sorbona en uno de sus dos libros fundamentales sobre la materia: el otro ${ }^{43}$ muestra bien cómo se sintió llamado Triclinio a componer unos escolios métricos a Píndaro que pusieran al día el tratado de Isaac Tzetzes, quien parece haber vivido entre 1110 y 1138 . En este aspecto la labor del tesalonicense resultó útil, no tanto para el texto del viejo lírico como por lo que toca al de sus escolios antiguos, muchas veces enmendados por él. Y, en cuanto a su trabajo de edición y comentario sobre el propio tebano, Triclinio, el testimonio básico de cuya recensión, un códice florentino ${ }^{44}$, está por desgracia mutilado, se revela, en la autorizada opinión de Irigoin ${ }^{45}$,

39 "Demetrios Triklinios ist in Wahrheit eher als der erste moderne TragikerKritiker zu führen denn als ein unzuverlässiger Vertreter der Ueberlieferung... Er besass aber auch gar nicht geringe metrische Kenntnisse, die er nicht den Lehrbüchern, sondern der Beobachtung entnahm».

40 Cf. H. Hunger, o. c. (en n. 1), p. 74.

41 Cf. n. 2.

42 J. Irigoin, o. c., p. 331

43 J. Irigoin, Les scholies métriques de Pindare, París 1958.

44 Cód. Flor. Laur. conv. suppr. $94\left(\alpha^{\prime}\right)$.

45 J. Irigoin, o. c. (en n. 28), pp. 331-364 (capítulo titulado «Un philologue moderne: Démétrius Triclinius $»$ ); cf. p. 361 ( $($ Triclinius est le premier philologue de cette époque à utiliser et à comparer plusieurs manuscrits pour en tirer la leçon qui lui paraît la meilleure; il est le premier à corriger son texte d'une manière souple et intelligente, qui dénote chez lui une connaissance de la métrique remarquable pour son temps. On pourra lui reprocher quelques excès dans ses corrections, des erreurs dans ses conceptions métriques; il n'en reste pas moins, par sa méthode, le premier en date des philologues modernes... Triclinius assure la liaison entre les principes hérités des philologues alexandrins, lentement dégradés au cours des siècles, et l'érudition nouvelle qui va se développer en Occident dès le xve siècle») comparado con H. Hunger, o. c. (en n. 1), p. 74 (awie Planudes war er bestrebt, seinen Ausgaben mehrere Textzeugen zugrundezulegen, eine Beobachtung, die für Moschopulos und Thomas keineswegs gilt») y con J. Irigoin, o. c. (en n. 43), p. 93 («était, pour son temps, un bon spécialiste de la métrique grecque»), p. 99 («connaît la métrique beaucoup mieux que ses prédécesseurs»), p. 105 («assez souvent, une conjecture attribuée dans l'édition Drachmann à un philologue du xvırre ou du xıxe siècle, a été déjà proposée par Triclinius... Triclinius, qui comme 
como el primer filólogo moderno, un eslabón entre los gramáticos alejandrinos, cuyos principios se habían ido degradando al paso de los siglos, y la nueva erudición que florecerá desde el xv; el único sabio de su época que utiliza y compara varios manuscritos para extraer la mejor lección y que corrige los textos de manera flexible e inteligente y con notables conocimientos de la Métrica, de la que se muestra buen especialista. Lo que ocurre es que, como todas las personas sensatas, el crítico se comporta a veces con indecisión y timidez.

Pínd. N. I 72. $\sigma \varepsilon \mu v \delta \delta$ $\alpha$ lv

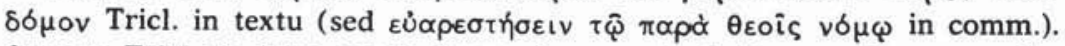
Aunque Tricl. ve bien que la buena lecc. es la de los escolios, no se ha atrevido a introducirla en el texto.

Pero en otras ocasiones su acierto resulta indudable.

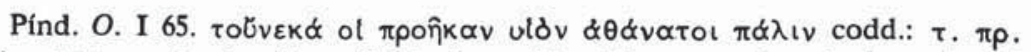

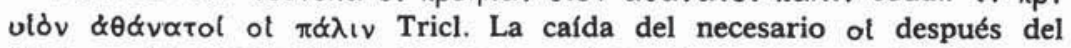
final -o tha provocado en los mss. su inclusión en lugar antimétrico.

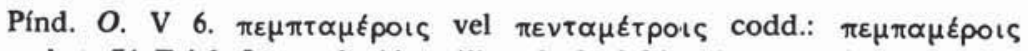
Pap. Ant. 76 Tricl. La evolución eólica de la labiovelar autoriza la forma confirmada por el pap.

En lo que concierne a Esquilo, no he tenido mucho tiempo para estudiar la labor tricliniana ni al parecer es tan meritoria como en cuanto a otros autores. Tenemos, es cierto, un autógrafo suyo en Nápoles ${ }^{46}$, con escolios a la tríada bizantina (Siete, Persas, Prometeo) y al Agamenón y Euménides que han ido publicándose, más recientemente los de los Persas en una buena edición de Lidia Massa Positano 47 ; pero ya antes Turyn ${ }^{48}$ había dedicado al códice un estudio profundo, como todos los suyos, al que han objetado Fraenkel ${ }^{49}$ y por último Dawe ${ }^{50}$, el cual plantea, como otros a que luego aludiremos, la importante cuestión de si no será demasiado audaz el considerar como conjeturas de

éditeur de Pindare rompt avec la tradition antérieure, est aussi un novateur en métrique; il est vraiment le premier des philologues modernes»).

46 Cód. Neapol. Farn. II F 31 (T).

47 L. Massa Positano, Demetrii Triclinii in Aeschyli Persas scholia, Nápoles 1948; cf. también «Osservazioni sull'edizione eschilea di Demetrio Triclinio, en Dioniso 10, 1947, pp. 247-265.

48 A. Turyn, The Manuscript Tradition of the Tragedies of Aeschylus, Nueva York 1943 (cf. res. de M. Fernández-Galiano en EMERITA 11, 1943, pp. 239-241), s. t. pp. 110-116.

49 E. Fraenkel, o. c., pp. 3-4.

so R. D. Dawe, The Collation and Investigation of Manuscripts of Aeschylus, Cambridge 1964, s. t. pp. $60-63$. 
Triclinio o de sus predecesores constantinopolitanos o tesalonicenses lo que pueden ser lecciones que ellos hallaran en códices perdidos. En todo caso, es a veces un tanto burdo el método con que el citado manuscrito (al que, por cierto, se suma otro ${ }^{51}$ no colacionado por Turyn y procedente del monte Athos) intenta resolver casos difíciles.

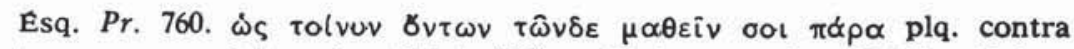

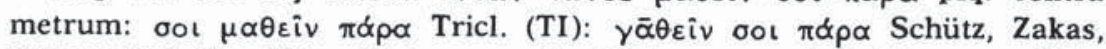

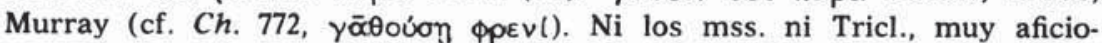
nado a las inversiones de palabras, pueden explicarse la por lo demás problemática conservación de $\bar{\alpha}$ en el equivalente de $\gamma \eta \theta \varepsilon \omega$.

Las tareas triclinianas en torno a Sófocles han sido bien estudiadas por Aubreton ${ }^{52}$ y Turyn ${ }^{53}$ : testimonio capital es el códice parisino ${ }^{54}$ utilizado por Turnèbe que antes mencionábamos ${ }^{55}$. El último de los autores modernos citados caracteriza bien los esfuerzos del bizantino, excelentes en cuanto a los trímetros, pero menos afortunados en sus retoques métricos.

A ello volveremos en seguida.

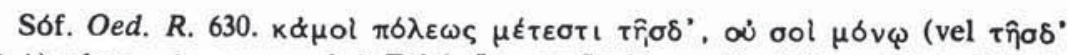

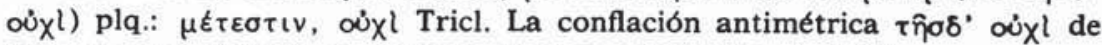
algunos mss. llevaba en germen la lecc. preferible de Tricl.

Porque donde realmente ha hecho este siglo sensacionales avances en relación con la labor de Triclinio es por lo que toca a Eurípides. El libro de Turyn sobre su tradición textual, publicado en 1957, contenía ${ }^{56}$ dos aportaciones dignas de la mayor atención. De una parte el hecho de que un códice de la Biblioteca Angélica de Roma, que contiene la tríada bizantina con escolios, es ${ }^{57}$ un autógrafo de nuestro filólogo que aporta luz clarísima sobre su modo de trabajar, del que dio otra prueba, casualmente en el mismo año, el hallazgo, debido a Koster ${ }^{58}$, de un manuscrito también autógrafo de París ${ }^{n}$ consagrado a otra tríada para-

51 Cód. Athous Iviron 209 (I).

52 R. Aubreton, o. c.

53 A. Turyn, Studies in the Manuscript Tradition of the Tragedies of Sophocles, Urbana, Ill., 1952 (cf. s. t. pp. 69-86 y en especial 69-70).

54 Cód. Paris. gr. 2711 (T)

55 Cf. n. 36.

56 A. Turyn, o. c. (en n. 4), s. t. pp. 23-52.

57 Cód. Rom. Bibl. Angel. gr. 14 (T).

58 W. J. W. Koster, Autour d'un manuscrit d'Aristophane écrit par Démétrius Triclinius. Etudes paléographiques et critiques sur les éditions d'Aristophane de l'époque byzantine tardive, Groninga 1957; cf. H. Hunger, o. c. (en n. 1), p. 75, n. 93. 59 Cód. Par. Suppl. gr. 463. 
lela de Aristófanes (Pluto, Nubes, Ranas). Trátese del trágico o del cómico, Demetrio toma otros códices de Moscopulo o de Tomás, los va revisando varias veces, amplía su comentario con los escolios métricos que constituyen su especial campo de interés, añade notas propias o ajenas y con ello va creando lo que pudiéramos llamar una edición personal; y, en el caso concreto del Angélico, puede apreciarse incluso el hecho de que ciertas hojas primitivas, correspondientes a textos corales, que probablemente quedaron en principio demasiado emborronadas 0 confusas, han sido simplemente arrancadas del manuscrito básico y sustituidas por folios copiados por el propio revisor. Y todo ello con resultados críticos no despreciables en cuanto a los trímetros yámbicos y extremadamente ambiciosos por lo que respecta a la métrica coral ${ }^{\infty}$.

Pero hay más aún. Son famosos los dos códices euripideos $\mathrm{L}^{61}$ y $\mathrm{P}^{62}$, a los que debemos el sublime beneficio de la transmisión de las tragedias alfabéticas salvadas milagrosamente, según demostró Snell ${ }^{63}$, por dos vasijas, correspondientes, en orden alfabético aproximado, a las letras E-K, de entre una serie de ellas que en algún lugar guardaban toda la obra de Eurípides archivada en grupos de cinco rollos, de los que nuestras dos ánforas contenían no sólo los nueve dramas en cuestión, sino también la Hécabe transmitida además por otras fuentes. $\mathrm{Ha}$ sido, en efecto, una gran fortuna la concatenación de circunstancias plasmada en tan bienhechores manuscritos: Zuntz, saliéndose por una vez de sus austeros estilo y argumentación, se pregunta ${ }^{64}$ si sería posible imaginar un mundo actual desconocedor del sacrificio de Ifigenia, el frenesí de Dioniso y Penteo, la gloria y la desgracia de Heracles. El caso es que por fortuna ambos códices existen; siempre se había pensado que $P$ era un simple apógrafo de L; Turyn se inclina más bien a creer que se trata de gemelos y además demuestra que en el último hay evidentes huellas autógrafas de la revisión a que sometió Triclinio a quince tragedias, todas menos la tríada y las Troyanas, ausente esta última del manuscrito florentino ${ }^{\text {} 5 . ~}$

60 A. Turyn, o. c. (en n. 4), pp. 188-205, s. t. 193-194.

61 Cód. Flor. Laur. plut. 32, 2 (L).

62 Códs. Rom. Vat. Palat. 287 y Flor. Laur. conv. suppr. 172 (P).

63 B. Snell, «Zwei Töpfe mit Euripides-Papyri», en Hermes 70, 1935, pp. 119-120.

64 G. Zuntz, o. c., p. XIX.

65 Puede ser útil aquí, al menos para no muy iniciados, una catalogación del complicado estado textual de las dieciocho tragedias de Eurípides seguramente auténticas más el quizá apócrifo Reso más la Dánae reducida al fr. 1132 N.: a) componente de la tríada y héptada y grupo alfabético, con escolios, en L, P y los demás mss. (Hécabe); b) de la tríada y héptada, con escolios, en L, P y los demás (Fenicias, Orestes); c) de la héptada, con escolios, en L, P y los demás (Alcestis, Andrómaca, Hipólito, Medea); d) con escolios, en L, P y los demás (Reso); 
Ocho años separaron el excelente libro de Turyn del no menos deslumbrador de Zuntz ${ }^{66}$. En él hallamos muy destacables conclusiones: que, contra la opinión del paleógrafo polaco-americano, P, aun no carente de calidad, es copia de $\mathrm{L}, \mathrm{y}$ ahí la divertida anécdota ${ }^{67}$ de la mota de paja que, incorporada a la contextura del papel, había sido considerada falsamente por el copista como un signo de puntuación; que si bien Triclinio, demasiado fiel al viejo Hefestión, suele recurrir ${ }^{68}$ con pueril jactancia ${ }^{69}$ a métodos procrusteos - cambios del orden de las palabras, las típicas adiciones de inocuos $\gamma \varepsilon$ o $\tau \varepsilon$ - para normalizar

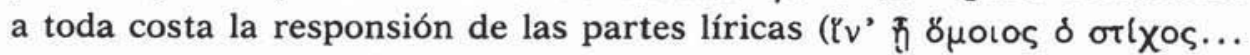

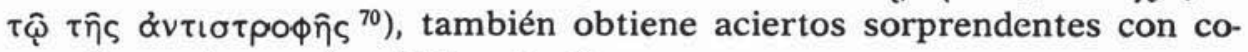
rrecciones de pasajes dialogados ${ }^{n}$.

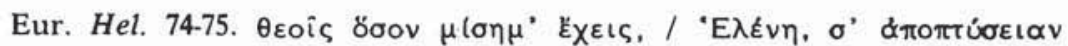

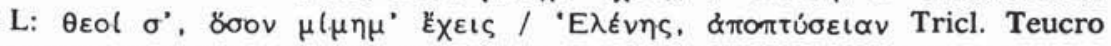
no puede hablar en voc. a Hélena, porque no sabe quién es; la razón

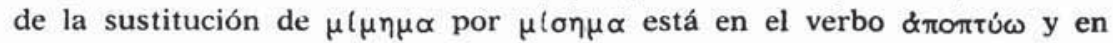
la general aparición de la esposa de Menelao como persona odiada; se maldice a esta mujer sólo porque se parece a ella; es sumamente elegante la solución, separando una supuesta - $\varsigma$ de su palabra y convirtiendo un supuesto pron. en desin. de gen.

Ahora bien, el autor nos siembra la duda ${ }^{72}$ con su convicción ${ }^{73}$ de que Turyn y otros son excesivamente optimistas en cuanto a la competencia de los filólogos de la época paleológica, y ello en relación no sólo con Triclinio, sino también con Moscopulo y Magíster. El sospecha que tres cuartas partes por lo menos de las nuevas lecturas de todos ellos proceden de códices hoy perdidos; y, en lo que toca al citado ejemplo de Eur. Or. 605-606, basa su desconfianza hacia una sagaz intuición de Tomás en el mismo principio de la lectio difficilior que ordinariamente aplicamos a los copistas medievales: si el filólogo encontró un

e) con escolios, en P y los demás (Troyanas); f) sin escolios, en L y P (Bacantes); g) sin escolios, fragmentariamente en $\mathrm{P}$ (Dánae); $h$ ) del grupo alfabético, sin escolios, en L y P (Ciclope, Electra, Hélena, Heracles, Heraclidas, Ifigenia en Aulide, Ifigenia entre los Tauros, Ión, Suplicantes).

66 G. Zuntz, o. c.

67 G. Zuntz, o. c., pp. 13-15 (sobre Hel. 95; el complicado stemma puede hallarse en p. 192).

68 G. Zuntz, o. c., pp. 194-196. 186.

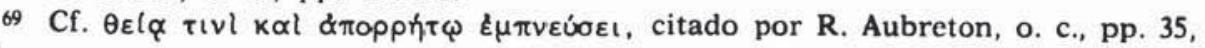

70 Cf. R. Aubreton, o. c., p. 166.

71 G. Zuntz, o. c., pp. 196-197.

72 G. Zuntz, o. c., pp. $151-160$ (s. t. 154 y 160) y 193-194.

73 Cf. H. Hunger, o. c. (en n. 1), p. 73. 
texto aparentemente razonable y sencillo, ¿cómo iba a sacarse de la cabeza una lección preferible, pero poco accesible a un hombre de cultura media? Ahora bien, si esto es así, preguntaríamos con todo respeto al ex profesor de Manchester cómo se explica que él mismo señale nuestro último ejemplo mencionado con llamativa negrita hablando de una conjetura digna de Porson o Hermann y por qué Wilamowitz, Aubreton, luego Tuilier ${ }^{74}$ en un libro al que no tengo ya tiempo de referirme, hablan de la sabiduría, de la genialidad, del talento de Triclinio.

En fin, tampoco la Filología puede sustraerse a las modas. Mucho me temo que hoy reine otra vez una tendencia a la baja en cuanto a Demetrio. Por de pronto me he entretenido en comparar los textos de las Suplicantes, Electra e Ifigenia entre los Tauros en la edición oxoniense de Murray ${ }^{75}$ y en la nueva de Diggle ${ }^{76}$, que en principio no me parece que vaya a eclipsar a su predecesora.

Una de las discrepancias es gramatical: se trata del bien conocido adverbio $\delta \propto l$, formado respecto a $\delta \dot{n}$ como val en relación con $v \grave{n}$, que aparece dudosamente en tres lugares de Homero (Il. X 408, Od. I 225, XXIV 299) y en los códices de Platón, de modo seguro en los cómicos y once veces en Eurípides, frecuentemente en lecciones triclinianas de L o P, de donde yo creo, a diferencia de la señora Dale en nota a Hel. 1246, que debe ser desterrado. Murray suele acogerlo incluso cuando es conjetura, pero con una inconsecuencia; algo parecido ocurre con Diggle, a quien, aunque adverso a él, se le escapa de vez en cuando.

Murray acepta $\delta \alpha$ ( procedente de los mss., Cycl. 450, Hel. 1246 (cf. Dale

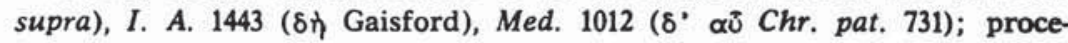
dente de conj., Med. 339 (Housman, mss. $\delta^{\prime} \alpha \overline{\mathrm{J}}$, Elmsley $\delta \eta$ ); lo rechaza,

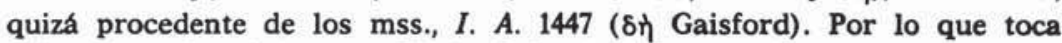
a las tragedias del tomo II de Oxford, único reeditado recientemente, Murray lo acepta procedente de los mss., mientras Diggle prefiere con-

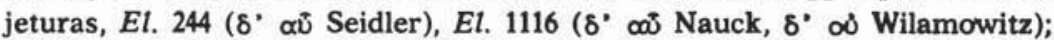
Murray y Diggle lo aceptan procedente de mss., Ion 275 ( $\delta \eta$ Elmsley, $\delta^{\circ} \propto \tilde{u}$ Porson); Murray y Diggle lo rechazan procedente de mss., El. 978 ( $\delta^{\prime}$ in Camper frente a un $\delta \alpha l$ imposible), El. $1303\left(\delta^{\prime} E \mu \mu^{\prime}\right.$ Seidler frente a un $\delta \alpha l$ antimétrico).

Otro de los problemas, demasiado complejo para ser tratado aquí, es el de $I$. T. 35, en que Triclinio leía un vófoı

74 A. Tuilier, Recherches critiques sur la tradition du texte d'Euripide, París 1968 (cf., p. ej., p. 208: «le disciple de Magister avait atteint la maturité et il pouvait donner toute la mesure de son talent... les conjectures nombreuses... révèlent la maitrîse du philologue»).

75 G. Murray, Euripides. Fabulae II, Oxford, reimpr. 1955.

76 J. Diggle, Euripides. Fabulae II, Oxford 1981. 
tivo en vez de relativo frente al que Diggle prefiere el vópoıøıv oløıv de Herwerden.

En Suppl. 1101, nuestro buen bizantino, con toda su sabiduría, no

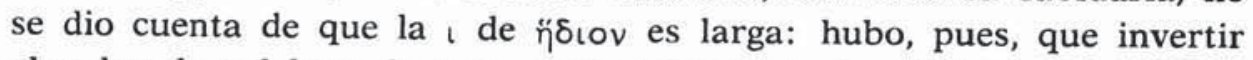
el orden de palabras, lo cual, para evitar hiato, ha obligado a sacrificar

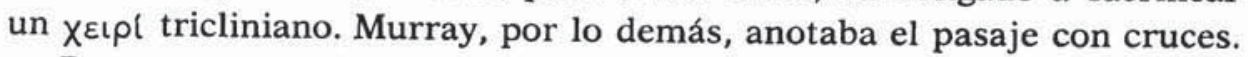

Pero voy a terminar ya con tres ejemplos. En el primero de ellos no sé si Triclinio tiene razón, porque hay razones a favor o en contra.

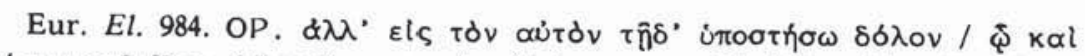

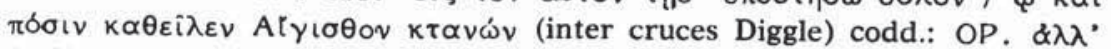

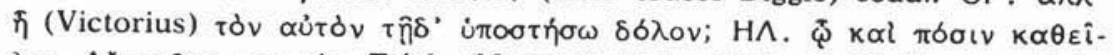

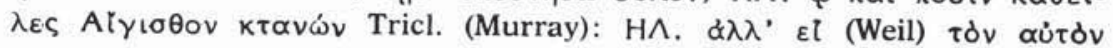

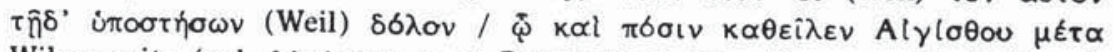

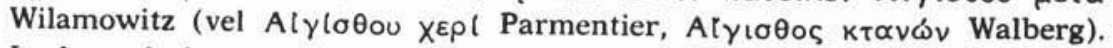
La lecc. de los mss., como ha visto Diggle, es insostenible. Tricl. atribuye a Orestes el verso 983 y a Electra el 984 , respetando mejor la esticomitia. Aun suponiendo que en $\varepsilon$ ls por $\lceil$ Tricl. haya dejado de enmendar una falta itacística corregida bien por Victorius, su lecc. tiene inconvenientes: a) $\tau \dot{b} v \alpha u ̛ \tau o v$ en boca de Orestes queda en el aire, sin término al que se refiera la identidad (pero esto puede ser uno de tantos casos en que la esticomitia hace necesario el corte); b) $\alpha \lambda \lambda^{\circ} \hbar$ en preguntas parece denotar sorpresa del interrogante, que aquí no se da; $c$ ) $\pi \delta$ ó. siado respetuoso en boca de Electra para referirse a Egisto, pero en 1116 lo emplea también (hablando, es cierto, a Clitemestra para engañarla) y puede ser irónico si el actor le daba el necesario retintín; d) el bizantino ha tenido que cambiar $\kappa \propto \theta \varepsilon i \hat{\lambda} \varepsilon \nu$ por $\kappa \alpha \theta \varepsilon i \lambda \varepsilon \varepsilon$. Otros filólogos prescinden de los parágrafos o indicaciones de interlocutor $\mathrm{y}$, considerando la esticomitia acabada en 981 , establecen dos tiradas paralelas de Electra (982-984) y Orestes (985-987). Weil está acertado en $\varepsilon l$, también itacístico

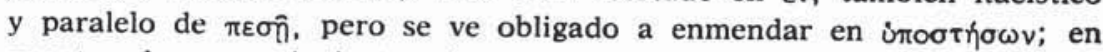
cuanto al verso siguiente, si con este reparto no se quiere escribir $\kappa \propto \theta \varepsilon \hat{\imath} \lambda \varepsilon \varsigma$ (Clitemestra, cf. Esq. Ch. 888, morirá a traición como mató, mientras que no tiene relevancia el hecho de que Orestes emplee el dolo dos veces) hay que cambiar o bien en Alyı $\sigma 0 \circ$ (Walberg, la traición frente a Clitemestra sería represalia de la de Egisto ante Agamenón) o bien excesivamente todo el final (Wilamowitz, Clitemestra mató a su marido con Egisto; Parmentier, le asesinó por medio de él).

En el segundo se revela brillantemente como un buen conocedor de la ambigüedad espiritual de lo $\gamma \lambda u \kappa u ́ \pi เ \kappa \rho o v$ que surge ya en la lírica arcaica.

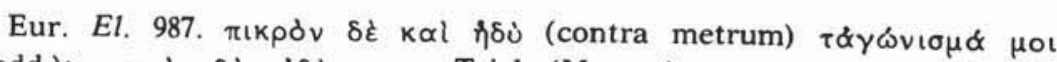

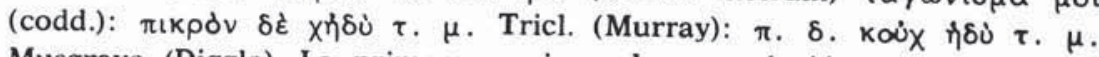
Musgrave (Diggle). La primera crasis es buena solución que describe la misión dulce y amarga (cf. Safo, fr. 130 L.-P.; Pínd. Thr. II 7) ante la que se halla el matricida; la conj. es de una banalidad inadmisible.

LIII, $10^{\circ}-3$ 
En el tercero cae en una trampa gramatical.

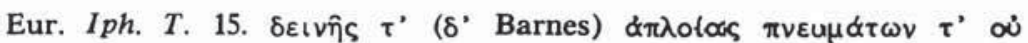
$\tau u \gamma \chi \alpha \nu \omega \nu$ Tricl.: $\delta . \delta^{\prime} \alpha \pi \lambda . \pi \nu$. $\tau \varepsilon \tau u \gamma \chi \alpha \nu \omega \nu$ Witzschel (Murray): $\delta \varepsilon เ v \hat{~}$ $\delta^{\prime} \alpha \pi \lambda$ ol $\alpha \pi \nu$. $\left.\tau^{\prime} \alpha \dot{\alpha} \tau\right\} \gamma \chi \alpha \dot{v} \omega v$ Madvig (Diggle). Es arbitrario el suponer

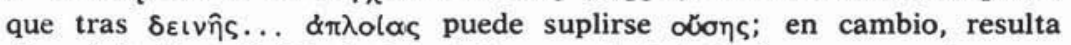
claro (cf. Tuc. II 85,6 , i $\pi^{\prime} \alpha^{\prime} v \varepsilon \mu \omega \nu \mathrm{k} \alpha \boldsymbol{\alpha} \alpha \pi \lambda$ ol $\alpha \varsigma$ ) que $\pi v \varepsilon \cup \mu \alpha \tau \omega \nu$ es capaz de significar "vientos adversos»; la situación en Aulide se hacía difícil porque o había calma chicha o el viento soplaba de proa; cf. Esq. Ag. 192-195, donde se dice que el viento venía del Estrimón, esto es, del NE.; la conj. de Madvig podría defenderse suponiendo un doble error de mayúsculas $\mathrm{I}>\mathrm{C}$, pero $\tau \varepsilon$ es bella lectio difficilior.

No miremos, pues, a Triclinio ni a sus meritorios colegas con la despectiva actitud de quien maneja constantemente, a diferencia de ellos, los textos de Oxford y el Liddell y el léxico de Collard y L'Année Philologique. Le debemos un admirativo recuerdo y una simbólica corona de filológico laurel en su centenario.

\section{Manuel Fernández-Galiano}

